\title{
ALFABETIZAÇÃO DE CRIANÇAS COM DEFICIÊNCIA MATRICULADAS NA REDE REGULAR DE ENSINO
}

\author{
Jacira Amadeu Mendes ${ }^{1}$ \\ Leonete Luzia Schmidt ${ }^{2}$
}

\begin{abstract}
Resumo
Este artigo tem por objetivo apresentar práticas de alfabetização possibilitadas às crianças com deficiência matriculadas em escolas da rede regular de ensino e sua implicação para a apropriação da leitura e da escrita. Trata-se de resultado de uma pesquisa exploratória realizada em turmas de 1 o e 3o ano do Ensino Fundamental de uma rede municipal de ensino da região sul de Santa Catarina. Os dados foram obtidos através de observações e entrevistas e sua análise evidencia que a proposta de atividade é a mesma para as crianças com deficiência e para as demais, não tendo, na maioria das vezes, a adaptação de material às necessidades específicas de cada deficiência.
\end{abstract}

Palavras-chave: Alfabetização. Crianças com deficiencia. Rede regular de ensino.

\section{LITERACY OF CHILDREN WITH DISABILITIES REGISTERED IN THE REGULAR EDUCATION NETWORK}

\begin{abstract}
This article aims to present literacy practices made possible to children with disabilities enrolled in schools of the regular school system and their implication for the appropriation of reading and writing. This is the result of an exploratory research carried out in first and third year classes of Elementary School in a municipal teaching network in the southern region of Santa Catarina. The data were obtained through observations and interviews and their analysis shows that the activity proposal is the same for children with disabilities and for the others, most times there is not adapted material to the specific needs of each disability.
\end{abstract}

Keywords: Literacy. Children with disabilities. Regular teaching network.

\section{ALFABETIZACIÓN DE NIÑOS CON DISCAPACIDAD MATRICULADOS EN LA RED REGULAR DE ENSEÑANZA}

\section{Resumen}

\footnotetext{
${ }^{1}$ Mestre em Educação pela Universidade do Sul de Santa Catarina. Professora de Educação Infantil no Município de Gravatal - SC e professora na Escola de Educação Especial Novo Horizonte (APAE) de Gravatal. Pedagoga da rede municipal de ensino de Gravatal, atuando como Coordenadora do Ensino Fundamental. Atualmente professora de Educação Infantil no Colégio Dehon. Participante do grupo de pesquisa alfabetização com letramento: formação inicial e continuada de professores da rede pública da região Sul de Santa Catarina. Experiência na área da Educação, com ênfase em Educação Infantil, Ensino Fundamental e Educação Especial. Email: <jacira.mendes@unisul.br>.

2 Doutorado pelo Programa de Pós-Graduação em Educação: História Política, Sociedade da Pontifícia Universidade Católica de São Paulo. Atualmente é professora do Curso de Pedagogia e do Mestrado em Educação da Universidade do Sul de Santa Catarina e vice coordenadora do Programa de Pós Graduação em Educação da Unisul, atuando principalmente nos seguintes temas: história da educação e história da educação de Santa Catarina; Educação básica; políticas públicas para educação; alfabetização. Coordenadora de um projeto de pesquisa do Programa Observatório da Educação - CAPES/OBEDUC. E-mail: <leonetes@gmail.com>.
} 
Este artículo tiene como objetivo presentar las prácticas de alfabetización puestas a disposición de los niños con discapacidad matriculados en escuelas de la red regular de enseñanza y su implicación para la apropiación de la lectura y de la escrita. Se trata del resultado de una investigación exploratoria realizada en clases de 1ㅇ e 3으o año de la Enseñanza Fundamental de una red municipal de enseñanza de la región sul de Santa Catarina. Los datos se han obtenido a través de observaciones y entrevistas y su análisis evidencia que la propuesta de actividad es la misma para los niños con discapacidad y para los demás, no teniendo, en la mayoría de las veces, la adaptación de material a las necesidades específicas de cada discapacidad.

Palabras-clave: Alfabetización. Niños con discapacidad. Red regular de enseñanza.

\section{INTRODUÇÃO}

Nas últimas décadas a educação passou por inúmeras mudanças, provocando alterações na organização e no funcionamento do ensino no país. Uma dessas mudanças está relacionada ao acesso de crianças com deficiência à rede regular de ensino.

O acesso dessas crianças à escola regular tem como referência a Política Nacional de Educação Especial na Perspectiva da Educação Inclusiva (BRASIL, 2008a), definida pela Resolução $\mathrm{CNE}^{3} / \mathrm{CEB}^{4}$ nํ 2, que institui Diretrizes Nacionais para a Educação Especial na Educação Básica e dispõe orientações que visam a garantir o acesso e a permanência dos alunos com deficiência, transtornos globais de desenvolvimento e alta habilidade/superdotação no sistema de ensino regular. A Resolução CNE/CEB no 4/2009 (BRASIL, 2009) institui Diretrizes Operacionais para o Atendimento Educacional Especializado na Educação Básica, dentre outras. Esses dispositivos legais norteiam a Educação Especial em instituições especializadas e na rede regular de ensino, preconizando normas e mudanças nos processos de escolarização das crianças com necessidades educacionais especiais.

A partir desses dispositivos as crianças com deficiência têm acesso assegurado à rede regular de ensino, o que não significa, necessariamente, condições de aprendizagem para a apropriação da leitura e da escrita na etapa da alfabetização. Esta questão requer um conjunto de ações e tomadas de decisão que ultrapassam o acesso à escola. São necessárias condições de infraestrutura, de trabalho e de formação para o professor e de recursos didáticos. Condições essas necessárias à concretização de uma prática pedagógica eficiente

3 CNE - Conselho Nacional de Educação.

${ }^{4}$ CEB - Câmara de Educação Básica. 
de modo que todas as crianças aprendam a ler e escrever nos três primeiros anos do Ensino Fundamental conforme determina a legislação atual.

Referente à etapa da alfabetização, de acordo com o Parecer do CNE/CEB no 22/2008 (BRASIL, 2008b), os três primeiros anos do Ensino Fundamental são dedicados ao processo de alfabetização, e são imprescindíveis para a qualidade da Educação Básica. Desde 2006, com a ampliação em um ano no tempo do Ensino Fundamental, todas as crianças devem ser matriculadas neste nível de ensino aos seis anos de idade, e têm os três primeiros anos destinados à alfabetização. Nesse contexto educacional, faz-se necessário saber se o que é disponibilizado às crianças com deficiência nesta etapa, nas classes de alfabetização de escolas de ensino regular, assegura a elas condições para a apropriação da leitura e da escrita ou se apenas estão matriculadas, cumprindo, assim, os requisitos legais, mas excluídas do processo de aprendizagem. Segundo Edler,

teoricamente são excluídos os que não conseguem ingressar nas escolas e também aqueles que, mesmo matriculados, não exercitam seus direitos de cidadania, de apropriação e construção de conhecimento. As estatísticas da educação brasileira permitem-nos conhecer os números de alunos que ingressam no ensino fundamental e dos que vão para o ensino médio. Ao compará-los evidenciam-se os elevados índices de excluídos que ocorrem, ainda, em nossas escolas (EDLER, 2004, p. 70).

Regina Leite Garcia, nos seus estudos sobre a alfabetização, diz que para que a escola possa ser um espaço que oportunize e potencialize a alfabetização de todos, principalmente daqueles de classes populares, é preciso desenvolver práticas que atendam às individualidades de cada aluno envolvido no processo educativo. Para essa autora, as práticas desenvolvidas nas escolas priorizam a homogeneização do saber, fato que culmina em exclusão daqueles que estão na escola, mas não se alfabetizam ou apresentam maior dificuldade (GARCIA, 2004).

As crianças com deficiência não são foco dos estudos da autora citada acima, mas, como historicamente estas foram também excluídas dos processos de escolarização, fazem parte das estatísticas dos não alfabetizados. $\mathrm{O}$ acesso delas às escolas de ensino regular pode possibilitar processos significativos de aprendizagem, se lhes forem oferecidas condições apropriadas. Os estudos de Vygotsky sobre aprendizagem e desenvolvimento evidenciam que todas as crianças aprendem, inclusive aquelas que apresentam deficiência, desde que sejam 
considerados, de forma conjunta, os aspectos que a constituem como ser humano, como as características biológicas, as experiências individuais e a herança sociocultural.

Para os alunos com deficiência incluídos nas escolas regulares, a mediação exercida pelos outros membros do grupo (professores, colegas, funcionários da escola) e pelos elementos da cultura que estão presentes no cotidiano escolar (ambiência, linguagem, materiais, conhecimento) contribui sobremaneira para a aprendizagem e, consequentemente, para o desenvolvimento de processos psicológicos cada vez mais elaborados.

Nesse sentido, conforme Bernal (2010, p. 87),

o desenvolvimento da criança com deficiência depende, em muito, da qualidade dessas vivências sociais, sejam elas aquelas que ocorrem no seio da família, no espaço escolar ou ainda no ambiente terapêutico, todos considerados espaços de aprendizagem.

Para essa autora, "a ação do outro, no contexto da interação social, caminha na direção de constituir aquilo que é típico do humano, auxiliando, favorecendo, encorajando, mas também atrapalhando, inibindo ou até mesmo impedindo esse processo" (2010, p. 87).

Ribeiro (2006, p. 122) explica que "toda aprendizagem é mediada pela interação social originária dentro de um contexto histórico-cultural mais amplo". Nesse contexto, a interação entre as crianças e outros sujeitos fundamenta os estímulos essenciais para o seu desenvolvimento, como uma espécie de suporte, de apoio inerente da condição humana. De acordo com Vygotsky, "um aspecto crucial da condição humana, e que começa na infância, é a criação e o uso de estímulos auxiliares ou 'artificiais'; através desses estímulos uma situação e as reações ligadas a ela são alteradas pela intervenção humana ativa" (VYGOTSKY, 2001, p. 175).

Na concepção do autor,

um aspecto essencial do aprendizado é o fato de ele criar zonas de desenvolvimento proximal; ou seja, o aprendizado desperta vários processos internos de desenvolvimentos, que são capazes de operar somente quando a criança interage com pessoas em seu ambiente e quando em cooperação com seus companheiros. Uma vez internalizados, esses processos tornam-se parte das aquisições do desenvolvimento independente da criança (VYGOTSKY, 1991, p. 117-118). 
Considerando que todas as crianças têm possibilidades de aprender, procurou-se saber como as crianças com deficiência são inseridas no espaço escolar e quais condições objetivas são proporcionadas a elas em relação à aprendizagem da leitura e da escrita nas classes de alfabetização.

Neste texto, o objetivo é apresentar práticas de alfabetização possibilitadas às crianças com deficiência matriculadas em classes de alfabetização e sua implicação para a apropriação da leitura e da escrita. ${ }^{5}$

O levantamento de informações foi realizado junto a duas escolas públicas de um município da região da Associação de Municípios da Região de Laguna (AMUREL), sul de Santa Catarina, que contavam com crianças com deficiência matriculadas no ensino regular. Em cada uma dessas escolas havia uma turma com uma criança com deficiência. Na Escola 1, turma de 3o ano do Ensino Fundamental, a criança, denominada aqui de Maria, tem diagnóstico de deficiência mental leve ( $\mathrm{CID}^{6} 10$ - F 70). Na Escola 2, turma do 1ำ ano, a criança possui paralisia cerebral (CID 10 - G 80), identificada, neste texto, com o nome de Joana.

Foram realizadas observações e entrevistas, sendo 8 (oito) observações em cada turma, com duração diária de 4 (quatro) horas cada, no período de agosto a dezembro do ano de 2012. Essas observações foram registradas, de forma escrita, em cadernos e através de imagens fotográficas das produções das crianças. As entrevistas com as mães e professores foram realizadas nas escolas, em horários agendados com cada participante e registradas através de gravações em câmera digital e, posteriormente, transcritas.

\section{A PRÁTICA PEDAGÓGICA NAS TURMAS DE MARIA E JOANA E SUA IMPLICAÇÃO PARA A APROPRIAÇÃO DA LEITURA E DA ESCRITA}

A prática pedagógica será entendida, neste texto, como ação desenvolvida no espaço de sala de aula, não uma simples ação, mas ações guiadas e imersas por intenções, em virtude de que nenhuma prática é neutra. Assim, a prática pedagógica referente às turmas de Maria e de Joana envolve o conjunto de ações que lhes são proporcionadas no período em

\footnotetext{
${ }^{5} \mathrm{O}$ texto é parte de uma pesquisa do projeto vinculado ao Programa Observatório da Educação intitulado "Alfabetização com letramento: a formação inicial e continuada e trabalho docente nas escolas da rede pública da região sul de Santa Catarina", desenvolvido entre 2010 e 2013.

${ }^{6}$ CID - Classificação Internacional de Doenças.
} 
que permanecem na escola, indo desde o espaço destinado à realização de atividades, processo de ensino e de aprendizagem até estratégias e recursos utilizados.

Sobre o espaço, constatou-se que as salas de aula onde estudam Maria e Joana, mesmo sendo instituições diferentes, têm sua organização bastante semelhante, assim como a decoração das paredes. As carteiras estão dispostas em filas, uma atrás da outra, e cada criança tem seu lugar determinado. Além disso, há um cartaz dos aniversariantes confeccionado pela professora e um espaço para os trabalhos das crianças, que, regra geral, são folhas com desenhos impressos pintados pelas crianças. Mantoan lembra que a sala de aula precisa:

[...] de um espaço para que o aluno desenvolva suas atividades livremente e também para conter a grande diversidade de materiais didáticos que a caracteriza. $\mathrm{O}$ arranjo do espaço físico reflete os princípios educacionais em que se apoia a dinâmica escolar e a prática pedagógica. Assim sendo, como o espaço é fundamental no processo de descoberta e construção do conhecimento [...] (MANTOAN, 1989, p. 97).

A forma como as salas são organizadas e utilizadas pelas professoras e crianças pode contribuir para a descoberta e construção de novos conhecimentos. O fato de estar toda a sala ocupada com carteiras e mesas e estas dispostas em fila limita, de certo modo, as possibilidades de movimento das crianças. Além disso, há pouco material para ser explorado nas salas observadas.

Além do espaço, as estratégias utilizadas em ambas as turmas são bastante semelhantes, independentemente do conteúdo que está sendo utilizado. Ou seja, embora com especificidades, há muita semelhança na prática pedagógica das duas turmas/escolas pesquisadas.

Na turma de Maria (Escola 1), predominam trabalhos individuais, embora haja, também, atividades em dupla e em grupo, estas geralmente, atividades com "lego", aulas de leitura e bingos realizadas em algumas aulas específicas. As atividades individuais são aquelas consideradas pelas professoras as mais importantes por estar relacionadas diretamente ao conteúdo de escrita e leitura, e, regra geral, são realizadas a partir dos livros didáticos e de cópias do quadro ou de exercícios de apostilas. Entretanto, essas atividades não são adaptadas para Maria, o que tornava difícil sua realização, visto que ela, na maioria das vezes, não 
compreendia as atividades propostas. Vale lembrar que na turma há outras duas crianças que não têm o domínio da leitura e da escrita. Observando a turma, fica evidente que a não alfabetização não ocorre apenas com Maria, mas também com crianças que não apresentam deficiência ou transtornos. Para estas não são oferecidas aulas de reforço escolar ou outro suporte pedagógico que as auxilie na aprendizagem. De acordo com Mantoan,

a reorganização das representações do real através de processos de abstração incluindo dados concretos, tangíveis ou não, são possíveis a partir da operação, ação interiorizada, reversível, que constitui o instrumento pelo qual o conhecimento lógico é produzido. Enquanto a operação não se instala, são oferecidas aos alunos experiências a partir das quais eles terão a oportunidade de caminhar em direção a ela, descobrindo propriedades e inventando relações sobre os dados do mundo físico e social (1989, p. 144).

Maria está frequentando o $3^{\circ}$ ano do Ensino Fundamental, é repetente desta série e ainda não domina a leitura e a escrita. Pelo fato de ela não saber ler e escrever ainda, as atividades precisam ser planejadas de modo que a levem a compreender a função da escrita e o domínio do código. Normalmente, Maria fica observando o que as demais crianças fazem e esperando auxílio de uma delas e/ou da professora.

Nas aulas de Arte, geralmente são disponibilizados desenhos impressos para pintar, que ficam dentro de uma caixa em cima da mesa da professora. Cada um escolhe o que gosta, pega e senta-se em dupla ou em pequenos grupos, conforme o interesse de cada um para pintar. Nessas aulas, Maria também vai à mesa da professora, pega um desenho e volta para sua cadeira e pinta. Em geral, fica sozinha.

Como se trata de uma prática frequente na turma, a questão que se apresenta é: de que forma, ou o que práticas como estas contribuem para a aprendizagem e o desenvolvimento das crianças? Por que são tão frequentes? Por que tantas outras formas de expressão artística são ignoradas na prática cotidiana da turma? Pôde-se perceber a falta de trabalhos com obras de artes, música, desenhos e demais temas que podem ser abordados nesta disciplina. Se se considerar que são as práticas sociais que possibilitam a aprendizagem, o limite de acesso a elas, logo, inviabiliza a aprendizagem.

Outro aspecto observado na turma da Maria diz respeito ao espaço para as aulas de Educação Física. Essas aulas acontecem na própria sala de aula por falta de espaço físico na escola. A professora disponibiliza jogos e desenhos. Eles mesmos se organizam em equipes 
ou em duplas e escolhem o que querem fazer. Os grupos pegam os jogos ou desenhos e quando querem mudar vão à mesa da professora e trocam. Em uma das aulas observadas, Maria foi convidada a jogar com três colegas. Quando eles a convidaram, ela apenas levantouse e foi até onde eles estavam. No momento do jogo somente mencionou duas vezes que era sua vez de jogar, e estava sorridente. Após jogar, ela foi desenhar junto com os mesmos colegas com quem estava jogando. Em todas as observações, esse foi o momento de maior interação entre ela e os colegas. Nos demais dias observados, ela ficou a maior parte do tempo sozinha, mesmo quando convidada pelos colegas para realizar atividades com eles. Quando ela está junto não fala nada, permanece em silêncio, apenas olha os desenhos dos colegas.

Diante dessa situação entre a aluna com deficiência e os demais, percebe-se que a interação não acontece de forma espontânea, e não houve, durante as observações, mediação por parte de professora para que a mesma interagisse com os alunos/atividades e com ela. Em uma das aulas, Maria ficou esperando a turma corrigir a tarefa das 7 h40min às 9 horas. Em alguns momentos, olhava para os colegas, para a professora, mostrando estar ansiosa, pois não tinha o que fazer.

Nesse contexto, fica inviável a apropriação da leitura e da escrita por uma criança com deficiência. As propostas desenvolvidas em sala de aula estão centradas em atividades repetitivas e, em sua maioria, individuais, dificultando os momentos de socialização entre as crianças e destas com as professoras.

A maioria das aulas é ministrada pela professora regente, que tem sua prática pedagógica centrada em aulas expositivas, com prevalência de atividades a serem realizadas individualmente, predominantemente de cópias. Não utiliza os livros didáticos disponibilizados pelo Ministério da Educação (MEC), pois, segundo ela, não correspondem às necessidades e realidade da turma. Em determinadas aulas fez uso de materiais concretos, como canudos de plástico, para ensinar a resolver contas de adição e subtrações.

A segunda professora ajuda com as atividades que a professora regente disponibiliza para todos. Via de regra, ela escreve as respostas para que Maria passe o lápis por cima do que ela escreveu. Após essas atividades, auxilia as demais crianças individualmente. Quando a segunda professora não está na sala, os alunos tentam auxiliá-la. A ajuda de que Maria precisa pode ser considerada uma necessidade de adaptação, que não é, obrigatoriamente, uma atividade a ser realizada pelos colegas da turma. Como ela não está 
alfabetizada numa turma em que a maioria já está, precisa de medições constantes para que essa apropriação aconteça.

Jannuzzi e Caiado (2013, p. 64) enfatizam que se deve "levar em conta todo conhecimento sistematizado, a começar pela alfabetização, usando métodos, técnicas e procedimentos adequados ao ensino, garantindo formação criadora para o mundo". Não apenas as crianças com necessidades educacionais especiais, mas todos têm direito ao ensino com diferentes técnicas e métodos que estimulem a criatividade para que possam se alfabetizar e, assim, ter condições de uma vida mais independente.

Verifica-se, na turma onde Maria estuda, que há dificuldades no relacionamento entre ela e as demais crianças, causando seu isolamento, além de falta de materiais adequados, de conhecimento por parte da turma sobre suas limitações e possibilidades de aprendizagem. Parece haver falta de compreensão por parte dos professores e equipe pedagógica sobre como deve acontecer o processo de inclusão de alunos com deficiência no ensino regular. Mas não se observa um movimento na busca por compreender, como poderia ser realizado um trabalho que viabilizasse a inclusão e a aprendizagem. Parece que há uma inércia sobre o que é necessário adaptar, como fazer as adaptações, como encaminhar para atendimento de outros profissionais, como: psicólogos, fonoaudiólogos e psicopedagogos.

As atividades propostas para Maria eram as mesmas oferecidas para as demais crianças. Era sempre orientada para esperar a professora, que primeiramente atendia as demais crianças. Em uma das situações observadas, Maria tentou copiar o que a professora passava, fez algumas tentativas de escrita, não conseguiu, ficou esperando. Quando a professora notou que ela havia copiado apenas algumas letras, apagou e fez para ela, sem questionar o que ela havia feito. Parecia desconsiderar que o que a menina havia feito era uma tentativa de escrita e que, neste caso, o que julgava ser um erro poderia ser considerado como uma "ponte" entre a zona de desenvolvimento real e a zona de desenvolvimento potencial, ou seja, o que ela fez "errado" é o que ela consegue fazer naquele momento na tentativa de fazer o que lhe é solicitado. Com a valorização do que ela faz e orientações, poderá fazê-lo da forma que chegue ao objetivo da atividade proposta.

A professora, antes de passar atividades no quadro, costuma dizer que não é para Maria copiar, pois ela deve fazer outra atividade. Com essa fala, todos os alunos voltam seus 
olhares para Maria. Percebe-se, em situações como esta, que ela se sente constrangida frente aos demais colegas.

Em uma situação observada, quando Maria recebeu ajuda/orientação detalhada da professora, escreveu de forma legível e coerente com as solicitações. No entanto, não é simples para ela realizar o que é proposto na sala de aula. Por um lado, há falta de constantes mediações e, por outro, há num mesmo dia diferentes conteúdos trabalhados a partir de atividades totalmente diferentes umas das outras, causando dificuldade de compreensão, como pode ser visto na figura 1.

Figura 1 - Atividades propostas para a turma de Maria

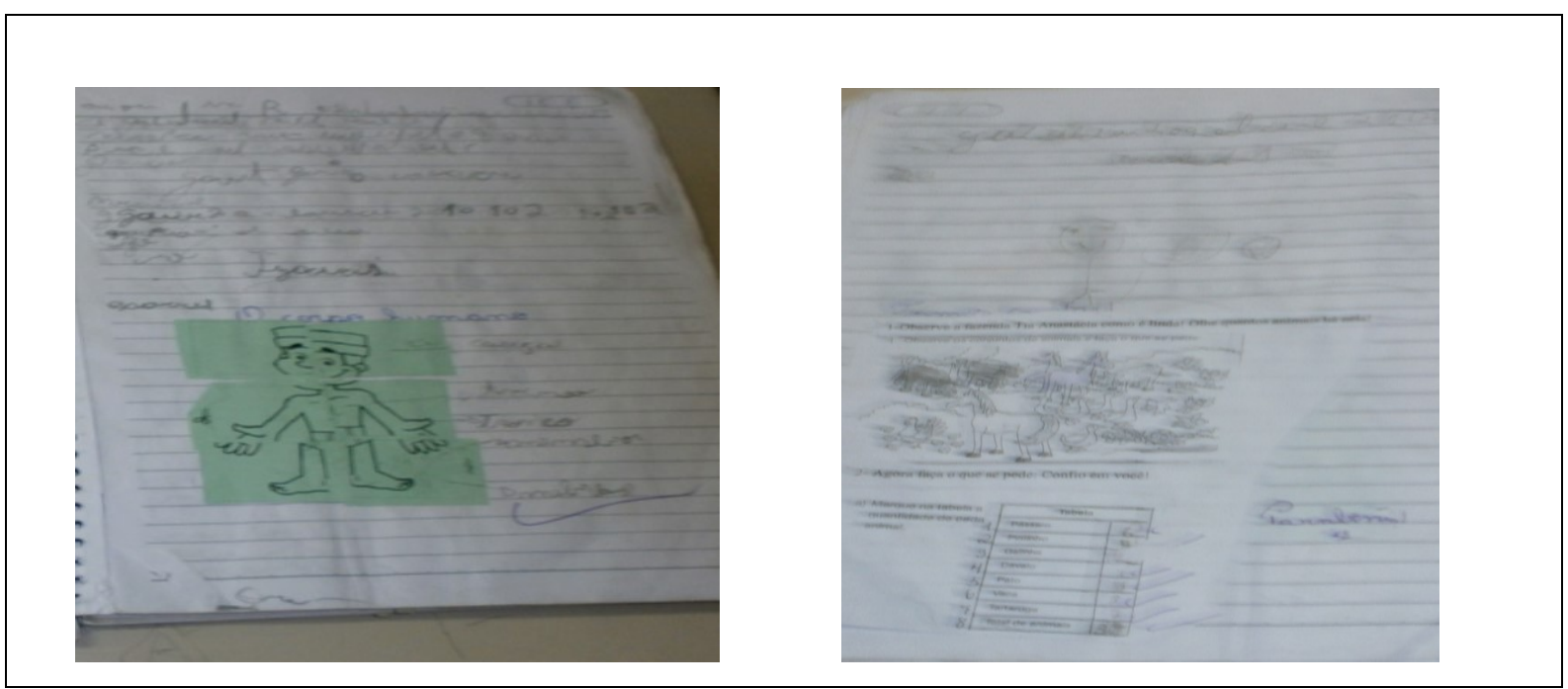

Fonte: Arquivo pessoal da pesquisadora, 2012.

As atividades constantes nas duas imagens foram passadas para toda a turma. Enquanto a turma realizava, a professora montou a gravura do corpo humano, colou no caderno de Maria e escreveu ao lado o nome de cada parte (imagem do lado esquerdo). $\mathrm{Na}$ sequência, deu a ela uma folha contendo três atividades diferentes (imagem do lado direito). Uma destas atividades era escrever a quantidade de cada espécie de animais que apareciam na gravura. Para uma criança com deficiência e que está na etapa de alfabetização, cada atividade, além de adaptada para sua necessidade, deveria vir acompanhada de demonstração/explicação. É preciso saber primeiro se ela percebe diferença entre os animais, e é necessário ser um tema que está sendo estudado. Da forma que foi proposta a atividade, ela não tinha a menor condição de realizá-la com compreensão. Mudar constantemente de 
assunto, como acontecia nas aulas daquela turma, deixava-a totalmente perdida e sem entender nada.

Nas aulas da turma da Joana (Escola 2), a professora regente, normalmente, inicia suas atividades corrigindo as tarefas e, em seguida, as crianças copiam a data do quadro. Joana não consegue copiar e necessita sempre da ajuda da professora, que vai até sua carteira e copia para ela. Quando a segunda professara está na sala, copia para Joana, que, na sequência, deve passar com o lápis por cima de cada letra.

Quanto à prática pedagógica da segunda professora, observa-se que esta limita a aluna a apenas fazer movimentos repetitivos, pois nem mesmo permite que ela desenvolva sua própria escrita.

A professora regente costuma realizar atividades como bingo de letras e atividades de pintura e maquete, sempre com as crianças sentadas em carteiras individuais. Mas o que domina na sua organização do tempo e do espaço são atividades com cópias de apostilas que trazem a escrita de palavras com as mesmas sílabas. Praticamente todas as atividades nessa turma são realizadas individualmente, o que dificulta a interação entre as crianças. Sabe-se que a comunicação entre elas desenvolve a aprendizagem. Na troca de experiências e nos conflitos vão sendo desenvolvidas habilidades de aprendizagem e de relações sociais.

Em algumas aulas, a segunda professora não estava na sala, assim a professora titular explicava a atividade a ser realizada no quadro para todos e orientava os alunos quando eles solicitavam auxílio. Joana não pedia ajuda e ficava esperando a professora ir à sua carteira. Quando esta a ajudava, geralmente apagava o que Joana havia feito e a orientava a fazer novamente ou copiava para ela e pedia para que pintasse os desenhos que faziam parte da atividade. 
Figura 2 - Atividade proposta para a turma de Joana

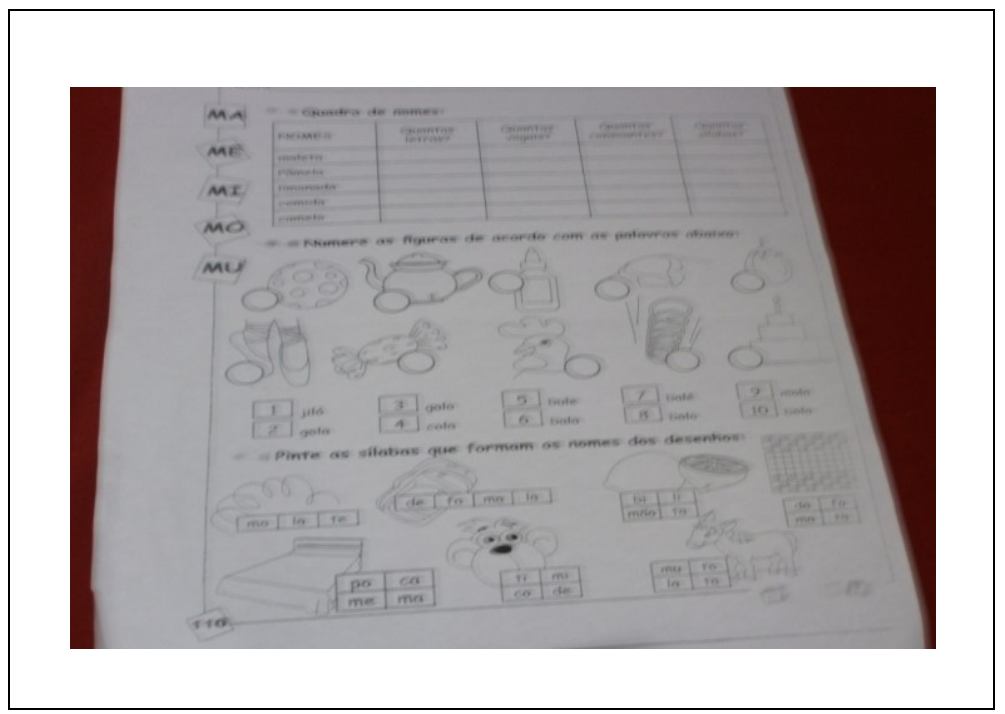

Fonte: Arquivo pessoal da pesquisadora, 2012.

Constata-se que, na mesma folha, havia três atividades diferentes: a primeira consistia em separar, na tabela, as vogais e as consoantes de cada palavra; a segunda, numerar as figuras de acordo com os nomes dispostos abaixo delas; a terceira pintar as sílabas para formar os nomes correspondentes às figuras. Essa atividade confundiu os alunos, que em geral tiveram dificuldades. Para Joana, que não reconhece as letras, tornou-se confusa e impossível de realizar.

Cabe mencionar que, quando a segunda professora está na sala, ela escreve as respostas e Joana passa o lápis por cima. Pôde-se verificar que as dificuldades da Joana não são apenas pela deficiência que apresenta, mas, também, pelas atividades propostas e pela forma como são apresentadas a ela. Ela não consegue compreender o que é proposto e apenas passa o lápis por cima do que lhe é solicitado.

Como Joana não reconhece as letras e números, não consegue escrever palavras ou identificá-las em leituras e/ou escritas, nem fazer contas. Segundo Vygotsky (1991), a zona de desenvolvimento real é entendida como as funções que a criança já consegue realizar sem mediação de outra pessoa, ou ciclos já contemplados. A zona de desenvolvimento proximal é a fase que a criança pode alcançar com mediação, ou seja, é o momento de visualizar o que se deseja alcançar. E com Joana, o que se percebe é que não é considerado o nível de conhecimento real dela, desconsiderando, assim, que a atuação deva ocorrer no nível proximal. 
Nas Educação Física, a professora costuma iniciar as aulas organizando um círculo para fazer alongamento. Em algumas atividades, Joana apresentava dificuldade nos movimentos, então a professora pedia para outras alunas a ajudarem ou ela mesma a auxiliava. Tal dificuldade era devido à deficiência física, mas com a ajuda de alguns colegas ou da professora Joana sempre conseguia realizar, mesmo com suas limitações.

Nas aulas de Arte, a professora prioriza as formas, os traços, os desenhos e outros elementos peculiares das aulas dessa disciplina. Numa dessas aulas, a professora propõe atividades de desenhos e estes exigem coordenação motora, fato que dificulta a realização devido à imobilidade do braço direito de Joana. Mesmo assim, Joana realiza a atividade, mas com dificuldades; quando não consegue, a professora ou uma outra criança a ajuda. Para esta atividade, a professora foi até o quadro, virou-se para a turma, falou que eles iriam desenhar figuras geométricas e fez alguns exemplos. Ela não demonstrou de forma diferenciada para Joana, que não entendeu o que era para fazer. Na tentativa de auxiliar, uma colega fez para ela, a professora aproximou-se e disse que não era para fazer por ela e sim ajudá-la, porém não orientou como deveria acontecer a ajuda a Joana.

Nos laboratórios de informática de ambas as escolas as crianças utilizam os computadores para jogar. Não há uma preparação de conteúdos específicos, cada um escolhe o que quer jogar entre os jogos disponibilizados no laboratório.

A formação dos profissionais da educação e as condições de trabalho e de remuneração podem ser entraves que dificultam o processo de alfabetização das crianças em geral e das com deficiência, de modo específico. Os profissionais que atuam em sala regular devem conhecer as condições das crianças com necessidades educacionais especiais para compreender como ocorre o seu desenvolvimento, o que caracteriza atraso cognitivo causado pela deficiência. O não conhecimento dos aspectos que caracterizam uma criança com necessidades educacionais especiais, ou como ocorre a aprendizagem e o desenvolvimento dessas crianças, pode estar contribuindo para que os professores permaneçam com práticas pedagógicas homogêneas, como se crianças com deficiência não precisassem de atividades adaptadas para desenvolver suas habilidades e ter a possibilidade de sonhar e realizar.

Move-me a busca dos sujeitos que são todos os deficientes mentais - sujeitos simbólicos, que mesmo com o mundo aos pedaços, continuam capazes de sonhar, imaginar, desejar, aprender e também amar. Eles esperam dos seus 
educadores maior compreensão de suas possibilidades e uma crença relativa nos diagnósticos médicos. Esperam poder participar do mundo cultural das pessoas consideradas normais (PADILHA, 2001, p. 43-44).

As atividades desenvolvidas nas escolas devem ir além da decodificação e codificação de sinais gráficos e decoração de conteúdos. Nas duas turmas, as crianças ficam limitadas a apenas reproduzir os conhecimentos que os professores julgam importantes, que parecem ser definidos sem considerá-los como parte do contexto social.

As aulas nas turmas da Joana e da Maria acontecem sempre da mesma forma, as professoras passam atividade ou conteúdo no quadro e, quando alguma criança não entende, explicam novamente do mesmo modo, sem levar em consideração os níveis de desenvolvimento de cada criança. Não é porque as crianças estão no 1 을 ano e no 3ㅇa ano que a assimilação dos conhecimentos científicos é igual para todas, sobretudo para crianças com diagnóstico de deficiência intelectual. Se as atividades fossem pensadas levando em conta o que elas conhecem e com mediação que possibilitasse a relação entre esse conhecimento e aquele que está sendo proposto, certamente haveria aprendizagem. As crianças com deficiência podem realizar a maioria das atividades propostas para o grupo desde que estas sejam adaptadas às suas condições e necessidades.

Cabe salientar que incluir não é algo fácil, exige trabalho diferenciado, pesquisa e dedicação. Frente a essas necessidades, é importante destacar que a organização e a reorganização da escola e da ação educativa são fundamentais para instituir as relações que promovam aprendizagem e desenvolvimento das crianças dentro de um ambiente escolar. Todavia, nas condições em que se encontram as escolas pesquisadas, observa-se que a inclusão é praticamente inviável. Embora não abordadas neste estudo, condições de trabalho, carreira e formação docente e infraestrutura das escolas são questões indispensáveis para a efetivação da inclusão nas escolas, pois, no entender de Maria Helena Souza Patto,

a falta de estabilidade do corpo docente, que se vê agravada pela maneira como se realizam os concursos e se remanejam docentes, encontra outro condicionante imediato no fato de que muitos professores, para fazer frente aos baixos salários, trabalham simultaneamente nas redes municipais e estaduais de ensino. A permanência em ambas requer astúcias e atenção aos dispositivos legais, o que resulta na prática de uma constante e complicada contabilidade, pois qualquer erro de cálculo pode ser fatal e resultar na perda indesejável do cargo numa das redes (PATTO, 1993, p. 190-191). 
Essa situação é a da maioria dos professores da rede municipal em que foi realizada a pesquisa, pois os mesmos professores que num período estão na rede municipal, noutro estão na estadual ou particular para assegurar uma remuneração melhor. É nesse contexto que as crianças com deficiência estão sendo inseridas nos processos de escolarização.

Hoje já existe uma série de recursos que permitem adaptação para diferentes deficiências, como, por exemplo, alfabeto com velcro, notebook com programas para deficientes visuais, deficientes físicos, mesas adaptadas, jogos adaptados, entre muitos outros que poderiam auxiliar no processo de alfabetização dos alunos com deficiência. Esses recursos são encontrados nas salas de recursos multifuncionais do município e outros na própria escola, porém não são utilizados com as duas crianças. Mantoan (1989, p. 102) afirma que "o material pedagógico da sala de aula deve ser variado, bem escolhido e apresentado". A variação de materiais faz com que os alunos se interessem por eles, por se tratar de novidade, e esta novidade proporciona novas aprendizagens. A escolha de materiais é importante e pode determinar a compreensão ou não do que está sendo proposto.

Para que os recursos pedagógicos sejam utilizados na escola, faz-se necessário que os professores tenham conhecimento de diferentes recursos didáticos que auxiliam no processo de ensino aprendizagem. De acordo com Manzini,

os dados dos vários estudos alertam que os recursos destinados ao ensino de leitura, escrita e matemática são pouco conhecidos e, infelizmente, os professores, em sua maioria, indicam não saber manusear esses recursos. Essa informação é bastante importante, pois, na realidade, os professores conhecem os processos de ensino e aprendizagem, porém necessitam incorporar informações sobre os recursos primordiais que poderão contribuir para o ensino de alunos com deficiência. Parece, pois, que uma alternativa de formação continuada para professores que trabalham com alunos com deficiência é avaliar essas lacunas e proceder formação específica para esse fim. Somente dessa forma, poderá ser conquistada a qualidade de ensino desejada para alunos com algum tipo de deficiência (MANZINI, 2011, p. 59-60).

Os recursos tecnológicos poderiam ser utilizados, nas duas escolas, tanto nas aulas em sala como nos laboratórios de informática e também na sala multifuncional do município. No entanto, não é isso o que ocorre, pelo menos até o momento desta investigação. 
A falta de uso dos recursos e materiais especializados durante as aulas dificulta o processo de ensino aprendizagem e fomenta a segregação. A criança com deficiência precisa sentir-se segura, acolhida e capaz de aprender, de se expressar.

O processo de ensino aprendizagem para as duas crianças com deficiência que frequentam a escola de ensino regular centra-se em práticas pedagógicas em que predominam o treino e a cópia em atividades individuais. As atividades são desenvolvidas para todos os alunos de forma homogênea, sem haver a preocupação de adaptá-las para atender às especificidades de Maria e Joana. Mesmo ambas não estando alfabetizadas, as atividades são realizadas como se já dominassem a linguagem escrita e a leitura.

Nas situações observadas nas duas escolas, percebeu-se que as crianças com deficiência atuavam muito pouco na zona de desenvolvimento proximal, pelo fato de ficarem a maioria do tempo fazendo aquilo que já dominam ou, em muitas ocasiões, nem isso, pois não entendiam o que era para ser feito. Não havia situações que as instigassem a pensar sobre a escrita e leitura no contexto social.

Conclui-se, portanto, que as crianças sujeitos da pesquisa não estão alfabetizadas, e com as práticas pedagógicas desenvolvidas nas escolas dificilmente irão se apropriar da leitura e da escrita. Estas não aparecem na prática pedagógica realizada nas duas turmas como prática social. Aparecem como práticas desarticuladas da realidade das crianças, talvez por falta de condições de trabalho e de formação dos professores e equipe pedagógica, assim como da inadequação dos espaços da sala de aula e das atividades propostas para esses alunos. O fato é que as duas meninas, uma do 1 o ano e outra do 30 ano do Ensino Fundamental, não têm encontrado, nas escolas onde estudam, condições para a apropriação da leitura e da escrita com possibilidades de delas fazer uso social.

\section{REFERÊNCIAS}

BERNAL, C. de M. F. Desenvolvimento e aprendizagem dos alunos com deficiência: subsídios da abordagem histórico-cultural. Polêmica, v. 9, n. 1, p. 84-91, jan./mar. 2010. Disponível em: <http://www.polemica.uerj.br/ojs/index.php/polemica/article/view/11/13>. Acesso em: fev. 2014.

BRASIL. Política Nacional de Educação Especial na Perspectiva da Educação Especial, MEC, 2008. Resolução CNE/CEB no 2, de 11 de setembro de 2008. Institui Diretrizes Nacionais para a Educação Especial na Educação Básica, DF, 2008a. 
. Parecer CNE/ no 4/2008. Define orientação sobre os três anos iniciais do Ensino Fundamental de nove anos. DF, 2008b.

Parecer CNE/CEB no 22/2009. Define diretrizes operacionais para a implantação do Ensino Fundamental de 9 (nove) anos, DF, 2009.

EDLER, C. R. Educação Inclusiva: com os pingos nos "is"/ Rosita Edler Carvalho. Porto Alegre: Mediação, 2004.

GARCIA, R. L. (Org.). Os novos olhares sobre a alfabetização. 2. ed. São Paulo: Cortez, 2004. Disponível em:

<http://www.anped.org.br/reunioes/27/gt15/t1510.pdf>. Acesso em: 9 jan. 2013.

JANNUZZI, G. de C; CAIADO, K. R. APAE: 1954 a 2013: Algumas reflexões. Campinas, SP: Autores Associados, 2013. (Coleção polêmicas do nosso tempo; 104).

MANTOAN, M. T. E. Compreendendo a deficiência mental: novos caminhos educacionais. São Paulo: Editora Scipione, 1989. (Série, pensamentos e ação no magistério).

MANZINI, E. J. In: BAPTISTA, C. R.; CAIADO, K. R. M.; JESUS, D. .M de. Professores e Educação Especial: formação em foco. Porto Alegre: Mediação /CDV/FACITEC, 2011. v. 2. p. 45-63. PADILHA, A. L. Práticas pedagógicas na educação especial: a capacidade de significar o mundo e a inserção cultural do deficiente mental. Campinas, SP: Autores Associados, 2001. (Coleção educação especial).

PATTO, M. H. S. A produção do fracasso escolar: história de submissão e rebeldia. São Paulo: T. A. Queiroz, reimpressão, 1993. (biblioteca de psicologia e psicanálise; v. 6).

RIBEIRO, J. C. C. Significações na escola inclusiva - estudo sobre as concepções e práticas de professores envolvidos com a inclusão escolar. 2006. 187 f. Tese (Doutorado)-Universidade de Brasília, Brasília, 2006. Disponível em: <http://repositorio.unb.br/handle/10482/3288>. Acesso em: 18 nov. 2013.

VYGOTSKY, L. S. A construção do pensamento e da linguagem. Tradução de Paulo Bezerra. São Paulo: Martins Fontes, 2001. (Psicologia e pedagogia).

. A formação social da mente: o desenvolvimento dos processos psicológicos superiores. Organização: Michael Cole et. al. Tradução de José Cipolla Neto, Luis Silveira Menna-Barreto, Solange Castro Afeche. 4. ed. São Paulo: Martins Fontes, 1991.

RECEBIDO EM 01 DE OUTUBRO DE 2016.

APROVADO EM 19 DE DEZEMBRO DE 2016. 